\title{
Health- and oral health-related quality of life among preschool children with cerebral palsy
}

\author{
Rennan Y. Du • Colman McGrath \\ Cynthia K. Y. Yiu • Nigel M. King
}

Accepted: 5 June 2010/Published online: 27 June 2010

(C) The Author(s) 2010. This article is published with open access at Springerlink.com

\begin{abstract}
Objectives To assess the health- and oral health-related quality of life of preschool children with cerebral palsy (CP) and to determine their inter-relationship between the two quality of life measures.

Methods A total of 144 preschool children with and without CP were invited to participate in the case-control study. Health-related quality of life was assessed by the Pediatric Quality of Life Inventory Version 4.0 (PedsQL ${ }^{\mathrm{TM}}$ 4.0) and oral health-related quality of life by the Early Childhood Oral Health Impact Scale (ECOHIS). Differences in PedsQL ${ }^{\mathrm{TM}} 4.0$ and ECOHIS scores were determined between the groups, and correlation between PedsQL and ECOHIS were explored.

Results Significant differences in overall scores of Peds$\mathrm{QL}^{\mathrm{TM}} 4.0(P<0.001)$ and in overall scores of ECOHIS $(P<0.05)$ were apparent between the two groups. In terms of health- and oral health-related quality of life, preschool children with CP fared worse than the age-gender-matched control group. There was a positive albeit weak correlation ( $r=0.203, P<0.05)$ between PedsQL ${ }^{\mathrm{TM}} 4.0$ and ECOHIS scores.

Conclusions Differences in health- and oral health-related quality of life exist among preschool children with $\mathrm{CP}$. Correlation between health- and oral health-related quality of life could at best be described as weak.
\end{abstract}

R. Y. Du · C. McGrath · C. K. Y. Yiu · N. M. King Faculty of Dentistry, The University of Hong Kong, Hong Kong SAR, China

R. Y. Du $(\bowtie)$

PDO, 2/F, The Prince Philip Dental Hospital, 34 Hospital Road,

Sai Ying Pun, Hong Kong

e-mail: rennandu@gmail.com
Keywords Cerebral palsy - Health-related quality of life · Oral health-related quality of life

\section{Introduction}

Cerebral palsy (CP) is the term used to describe a group of disorders, which affect movement and posture, causing activity limitation, that are attributed to non-progressive disturbances that occurred in the developing fetal or infant brain [1]. The true worldwide prevalence and incidence of $\mathrm{CP}$ are unknown, which in part relates to the fact that $\mathrm{CP}$ often goes undiagnosed until early childhood. The prevalence of CP among live births has been estimated to be 2.1/ 1000 in Europe [2] and 3.6/1000 in the United States of America [3]. In China, the incidence of $\mathrm{CP}$ among children aged 1 to 6 is $1.9 / 1000$ [4]. It has been suggested that between 70 and $80 \%$ of $\mathrm{CP}$ cases can be attributed to prenatal factors, such as hypoxia; with birth asphyxia being responsible for only a small number of cases (approximately 10\%); with the remainder being attributed to identifiable postnatal conditions [5].

Cerebral palsy is associated with numerous general health issues, because gross motor function is affected to a varying extent; usually presenting with asymmetric gross motor function or unusual muscle stiffness or floppiness [6]. Several medical complications are associated with this, including spasticity, joint contractures, hip dislocation, and spinal disorders [7]. Gastrointestinal problems are also common and include dysphagia, gastroesophageal reflux, gastritis, chronic pulmonary aspiration, and constipation [8, 9]. Epilepsy, visual impairment, hearing loss, and intellectual disability are also frequently encountered sequelae [7].

The oral manifestations associated with $\mathrm{CP}$ are changes in the structure of the orofacial region, development of 
parafunctional habits, which include swallowing and drooling problems; the affected individual also experience difficulties in maintaining acceptable levels of oral hygiene [10]. A better understanding of how the various general health-related issues affect the daily lives of $\mathrm{CP}$ children by using health-related quality of life (HRQoL) assessments has proven to be of value to health care workers [11]. However, to date no assessment of oral health-related quality of life (OHQoL) has been undertaken among children with $\mathrm{CP}$. Assessment of OHQoL would be valuable to draw attention to how oral health-related issues affect the daily lives of children with CP. In addition, it would facilitate comparing their OHQoL with other child populations, including other special needs groups, so as to prioritize oral health care measures.

This study aimed to assess and compare health- and oral health-related quality of life among preschool children with and without $\mathrm{CP}$ and to determine the correlation between health- and oral health-related quality of life assessments.

\section{Materials and methods}

Sample

The sampling frame for this study was the complete list of Special Child Care Centers as identified from the Government Social Welfare Department, Hong Kong Special Administrative Region (HKSAR), China. Thirty-three centers were identified, among which 23 centers had preschool children diagnosed to have CP (5 in Hong Kong Island, 5 in Kowloon, 13 in New Territories). In total, 94 children were identified from the 23 centers, and their parent(s)/primary care givers were invited to participate in the study. As a control group, an age and gender-matched sample of preschool children from mainstream preschools in the geographical areas were recruited. The study was approved by Institutional Review Board of Ethics (IRB HKU: UW 08-448). The sample required for the study was based on the size necessary to assess correlation between HQoL and OHQoL agreement on the assumption that it would be weak ( $r=0.30$ or less). Consequently, with at 0.05 and $B$ at 0.2 , a sample size of at least 84 subjects was deemed to be required to have $80 \%$ power.

\section{Data collection}

Health-related quality of life was assessed using the Chinese version of the Pediatric Quality of Life Inventory, PedsQL Version 4.0 [12], which consists of 23 items, covering four domains: physical functioning (8 items), emotional functioning (5 items), social functioning (5 items), and school functioning (5 items). The responses to each item are scored on a 5-point Likert scale to assess the frequency of an event occurring (0-never, 1-almost never, 2-sometimes, 3-often, 4-almost always). Scores for individual domains are then derived by computing responses to items within the domain, and an overall score is subsequently obtained by summating the responses to all items (score 0-92). A higher score indicates poor healthrelated quality of life.

Oral health-related quality of life was assessed using the Chinese version of the Early Childhood Oral Health Impact Scale (ECOHIS) [13]. The ECOHIS consists of 13 items, covering 6 domains: child symptoms domain (1 item), child function domain (4 items), child psychological domain (2 items), child self-image/social interaction domain ( 2 items), parent distress domain ( 2 items), and family function domain ( 2 items). Responses to each item are scored on a 5-point Likert scale to assess the frequency of an event occurring (1-never, 2-hardly ever, 3-occasionally, 4-often, 5-very often). Scores for individual domains are derived by computing the responses to items within the domain, and an overall score is obtained by summating responses to all items (score 13-65); a higher score indicates poor oral health-related quality of life.

Questionnaires of The PedsQL ${ }^{\mathrm{TM}} 4.0$ and ECOHIS attached with informed consent were self-completed by primary care givers and blind of clinical examinations.

\section{Data analysis}

The PedsQL ${ }^{\mathrm{TM}} 4.0$ and ECOHIS were commuted using SPSS for Windows version 16.0. Variations in PedsQL ${ }^{\mathrm{TM}} 4.0$ and ECOHIS between the $\mathrm{CP}$ and the non-CP groups were assessed using Mann-Whitney $\mathrm{U}$ test (a non-parametric equivalent to the $t$-test). The magnitude of the statistical difference was determined by calculating effect sizes (ES) for non-parametric data [14]. Correlations between the PedsQL ${ }^{\mathrm{TM}} 4.0$ and ECOHIS scores were explored by determining Spearman's correlation coefficient.

\section{Results}

Response rate and profile

Most of the parents and care givers who had children with CP $(78.7 \%, 74 / 94)$ gave their consent for their child to participate in the study. Two parents failed to complete the quality of life assessments and were excluded from the analysis, bringing the overall response rate to $76.6 \%$. The mean age of the children was $56 \pm 12$ months (range from 30 to 77 months), of whom $54 \%$ were boys. The characteristics of the participants with $\mathrm{CP}$ are presented in Table 1. An age and gender-matched control group of 
Table 1 The characteristics of the 72 preschool children with cerebral palsy

\begin{tabular}{llrr}
\hline Characteristics & Classification & $N$ & $\%$ \\
\hline Type of motor impairment & Spastic & 44 & 61.1 \\
& Non-spastic & 28 & 38.9 \\
Topographic classification & Monoplegia & 1 & 1.4 \\
& Hemiplegia & 10 & 13.9 \\
& Diplegia & 15 & 20.8 \\
& Quadriplegia & 40 & 55.6 \\
Gross motor function classification system & Unclassified & 6 & 8.3 \\
(GMFCS)[24] & Level I & 7 & 9.7 \\
& Level II & 12 & 16.7 \\
& Level III & 8 & 11.1 \\
& Level IV & 10 & 13.9 \\
& Level V & 33 & 45.8 \\
& Unclassified & 2 & 2.8
\end{tabular}

preschool children from mainstream preschools was also recruited. There was no statistically significant difference in the gender or age of the two groups $(P>0.05)$. Family income levels were comparable between the groups: study group (23.6\% 17/72 had a family income level of HK $\$ 20,000$ or above) versus control group $(16.7 \% ; 12 / 72$ had a family income level HK $\$ 20,000$ or above). Likewise, parental educational attainment (highest level of formal education among the parents) was similar between the study and control group (study group 81.9\% 59/72 attained high school qualification or above, versus 93.0\% 67/72 attained high school qualification or above in the control group).

Significant differences $(P<0.001)$ in overall PedsQL ${ }^{\mathrm{TM}}$ 4.0 scores were apparent between the two groups (Table 2). In addition, there were significant differences in the Peds$\mathrm{QL}^{\mathrm{TM}} 4.0$ sub-domain scores of physical functioning $(P<$ $0.001)$; emotional functioning $(P<0.001)$; social functioning $(P<0.001)$; and school functioning $(P<0.001)$. The effect size [15] difference in the overall PedsQL ${ }^{\mathrm{TM}} 4.0$ score was $1.65 ; 1.87$ for physical functioning, 0.84 for emotional functioning, 1.29 for social functioning, and 1.17 for school functioning.
Table 3 displays the mean ECOHIS scores for the $\mathrm{CP}$ and control groups. Significant differences in overall ECOHIS scores were apparent between the two groups $(P<0.05)$. The effect size difference in overall ECOHIS score was 0.55 . In addition, there were significant differences in ECOHIS sub-domain scores of child impact score $(P<0.05)$, child function domain $(P<0.05)$, child psychological domain $(P<0.05)$, and parent distress domain $(P<0.05)$, with effect size of $0.50,0.56,0.34,0.46$, respectively.

Correlation between PedsQL ${ }^{\mathrm{TM}} 4.0$ score and ECOHIS scores was calculated based on $72 \mathrm{CP}$ subjects and 72 ageand gender-matched control subjects, which identified a significant relationship $(r=0.203, P=0.015)$ between PedsQL $^{\mathrm{TM}} 4.0$ score and ECOHIS scores (Table 4). Across the sub-domains of the two measures, the correlation ranged from 0.007 to 0.236 . The strongest correlation was between the physical functioning sub-domain of PedsQL ${ }^{\mathrm{TM}}$ 4.0 and the child impact score sub-domain of ECOHIS.

\section{Discussion}

The response rate to this study was high indicating the feasibility of employing $\mathrm{HQoL}$ and $\mathrm{OHQoL}$ assessments among special needs groups. The mean PedsQL score of 43.39 was indicative of considerable adverse effects on HQoL compared to what has been previously reported in other preschool child populations [non-CP] [16, 17]. Moreover, in our study there was a statistically significant difference in PedsQL scores between the CP group and the control group of mainstream preschool children, indicating that preschool children with $\mathrm{CP}$ in Hong Kong are more compromised physically, emotionally, and socially. The magnitude of the statistical difference in overall PedsQL scores and across the domains can be considered to be large $(>0.80)$.

The mean ECOHIS score among the CP group was 19.03, which is higher than that has been identified in other preschool children assessments [18, 19]. Moreover, compared to the control group of preschool children in our study, there was significant difference in the overall ECOHIS sores, the sub-scale of child impact, and the sub-domains of child

Table 2 Comparison of PedsQL among preschool children with and without cerebral palsy

\begin{tabular}{|c|c|c|c|c|c|c|c|c|c|}
\hline \multirow[t]{2}{*}{ PedsQL Score } & \multirow[t]{2}{*}{ Possible range } & \multicolumn{2}{|c|}{ Floor effect } & \multicolumn{2}{|c|}{ Ceiling effect } & \multicolumn{2}{|l|}{ Mean (SD) } & \multirow[t]{2}{*}{$P$ value } & \multirow[t]{2}{*}{ Effect size } \\
\hline & & $\mathrm{CP}$ & Non-CP & $\mathrm{CP}$ & Non-CP & $\mathrm{CP}$ & Non-CP & & \\
\hline Overall & 0-92 & $8 \%$ & $22 \%$ & $0 \%$ & $0 \%$ & $43.29(22.20)$ & $13.75(12.03)$ & $<0.001$ & 1.65 \\
\hline Physical functioning & $0-32$ & $11 \%$ & $56 \%$ & $11 \%$ & $0 \%$ & $18.50(10.97)$ & $2.89(4.33)$ & $<0.001$ & 1.87 \\
\hline Emotional functioning & $0-20$ & $18 \%$ & $44 \%$ & $0 \%$ & $0 \%$ & $6.14(4.15)$ & $2.99(3.30)$ & $<0.001$ & 0.84 \\
\hline Social functioning & $0-20$ & $14 \%$ & $39 \%$ & $0 \%$ & $0 \%$ & $8.56(4.73)$ & $3.22(3.42)$ & $<0.001$ & 1.29 \\
\hline School functioning & $0-20$ & $13 \%$ & $24 \%$ & $3 \%$ & $0 \%$ & $10.10(5.55)$ & $4.65(3.56)$ & $<0.001$ & 1.17 \\
\hline
\end{tabular}


Table 3 Comparison of the ECOHIS scores among preschool children with and without cerebral palsy

\begin{tabular}{|c|c|c|c|c|c|c|c|}
\hline \multirow[t]{2}{*}{ ECOHIS whole score } & \multirow[t]{2}{*}{ Possible range } & \multicolumn{2}{|c|}{ Floor effect } & \multicolumn{2}{|l|}{ Mean (SD) } & \multirow[t]{2}{*}{$P$ value } & \multirow[t]{2}{*}{ Effect size } \\
\hline & & $\mathrm{CP}$ & Non-CP & $\mathrm{CP}$ & Non-CP & & \\
\hline Overall & $13-78$ & $35 \%$ & $40 \%$ & $19.03(6.36)$ & $16.10(4.09)$ & $0.016^{*}$ & 0.55 \\
\hline Child Impact & $9-54$ & $39 \%$ & $49 \%$ & $13.03(4.38)$ & $11.15(3.03)$ & $0.017 *$ & 0.50 \\
\hline Child symptoms domain & $1-6$ & $75 \%$ & $61 \%$ & $1.39(0.76)$ & $1.58(0.85)$ & 0.090 & - \\
\hline Child function domains & $4-24$ & $54 \%$ & $68 \%$ & $7.25(4.46)$ & $5.28(2.13)$ & $0.015^{*}$ & 0.56 \\
\hline Child psychological domain & $2-12$ & $74 \%$ & $88 \%$ & $2.60(1.13)$ & $2.26(0.82)$ & $0.032 *$ & 0.34 \\
\hline Child social interaction domain & $2-12$ & $94 \%$ & $90 \%$ & $2.15(0.78)$ & $2.22(0.74)$ & 0.346 & - \\
\hline Family impact & $4-24$ & $58 \%$ & $68 \%$ & $6.00(2.93)$ & $4.94(1.62)$ & 0.059 & - \\
\hline Parent distress domain & $2-12$ & $60 \%$ & $74 \%$ & $3.26(1.74)$ & $2.58(1.12)$ & $0.022^{*}$ & 0.46 \\
\hline Family function domain & $2-12$ & $74 \%$ & $83 \%$ & $2.74(1.46)$ & $2.36(0.89)$ & 0.127 & - \\
\hline
\end{tabular}

$* P<0.05$

Ceiling effect $0 \%$

Table 4 The correlation values between the ECOHIS and PedsQL measures

\begin{tabular}{llllll}
\hline ECOHIS and sub-domains & \multicolumn{2}{l}{ PedsQL and sub-domains } & & \\
\cline { 2 - 6 } & Overall & Physical functioning & Emotional functioning & Social functioning & School functioning \\
\hline Overall & $0.203^{*}$ & $0.246^{* *}$ & $0.220^{* *}$ & $0.185^{*}$ & $0.109^{\mathrm{ns}}$ \\
Child impact & $0.196^{*}$ & $0.236^{* *}$ & $0.211^{*}$ & $0.182^{*}$ & $0.105^{\mathrm{ns}}$ \\
Child symptoms & $0.074^{\mathrm{ns}}$ & $0.058^{\mathrm{ns}}$ & $0.193^{*}$ & $0.086^{\mathrm{ns}}$ & $0.018^{\mathrm{ns}}$ \\
Child function & $0.150^{\mathrm{ns}}$ & $0.181^{*}$ & $0.104^{\mathrm{ns}}$ & $0.169^{*}$ & $0.088^{\mathrm{ns}}$ \\
Child psychological & $0.185^{*}$ & $0.221^{* *}$ & $0.188^{*}$ & $0.126^{\mathrm{ns}}$ & $0.125^{\mathrm{ns}}$ \\
Child social interaction & $0.009^{\mathrm{ns}}$ & $0.008^{\mathrm{ns}}$ & $0.051^{\mathrm{ns}}$ & $0.007^{\mathrm{ns}}$ & $-0.028^{\mathrm{ns}}$ \\
Family impact scale & $0.135^{\mathrm{ns}}$ & $0.166^{*}$ & $0.162^{\mathrm{ns}}$ & $0.141^{\mathrm{ns}}$ & $0.053^{\mathrm{ns}}$ \\
Parent distress domain & $0.202^{*}$ & $0.223^{* *}$ & $0.218^{* *}$ & $0.205^{*}$ & $0.112^{\mathrm{ns}}$ \\
Family function domain & $0.055^{\mathrm{ns}}$ & $0.107^{\mathrm{ns}}$ & $0.077^{\mathrm{ns}}$ & $0.021^{\mathrm{ns}}$ & $0.013^{\mathrm{ns}}$ \\
\hline
\end{tabular}

ns $P>0.05 ; * P<0.05 ; * * P<0.01 ; * * * P<0.001$

function and child psychology. The magnitude of the statistical difference in overall ECOHIS scores and across the domains can be considered to be medium (around 0.5) [20]. In terms of family impact, children with $\mathrm{CP}$ had higher mean scores than the normal preschool children who were of borderline significance. Of note was that the parents of $\mathrm{CP}$ children reported higher parental distress, because of their children's oral health than did the parents of non-CP preschool children suggesting that the oral features associated with CP cause the parents considerable upset. It would be useful to conduct further studies among $\mathrm{CP}$ children in other global settings to facilitate comparisons of OHQoL in different communities. Furthermore, it would be useful to compare the findings of this study with other special needs communities to distinguish whether OHQoL is more compromised among children with CP or not; this would aid in the prioritization of oral health care measures for special needs patients.
A possible limitation of this study is that consideration of subject's clinical oral health assessment was not undertaken. If it plausible that clinical oral health status may account for some of the difference in HQoL and OHQoL between the $\mathrm{CP}$ and non-CP group. However, there is a general consensus that oral clinical parameters are not necessarily correlated with subjective views of oral health [21]. An additional limitation of the study is that the samples were matched for age and gender only; other socio-demographic factors (family educational attainment/ income) may have influenced HQoL and OHQoL values [22]. Nevertheless, there was no significant difference in parental educational attainment or family income between the two groups that were studied.

There was a significant correlation between HQoL as assessed by PedsQL and OHQoL as assessed by ECOHIS; but the strength of this correlation (Spearman's correlation $<0.30$ ) could at best be described as weak [23]. This 
suggest that inclusion of OHQoL measures can provide a more comprehensive assessment of impact of health status on QoL, by considering oral health impacts as well since HQoL and OHQoL, as this study demonstrated is poorly correlated. This suggests that HQoL assessments in themselves do not provide an adequate assessment of OHQOL and that there is a need to consider the inclusion of $\mathrm{OHQOL}$ to facilitate separate assessment of the oral health effects associated with CP. This study draws attention to the difference not only in HQoL but also OHQoL among children with CP. It is intended to raise awareness of oral health problems among special needs group and its impact on QoL. It would be useful in future studies to investigate the sensitivity of ECOHIS with respect to classification of $\mathrm{CP}$, where adequate numbers exist within each sub-category.

\section{Conclusions}

In conclusion, this study provided an assessment of $\mathrm{HQOL}$ (using PedsQL) and OHQoL (using ECOHIS) for preschool children with CP in Hong Kong. These assessments are useful reference values for HQoL and OHQoL of children with $\mathrm{CP}$. The HQoL and $\mathrm{OHQoL}$ were significantly more compromised among children affected by $\mathrm{CP}$ than for preschool children without $\mathrm{CP}$, highlighting the effects that CP has on general and oral health. The PedsQL had a weak correlation with ECOHIS indicating that HQoL assessment may be inappropriate for capturing OHQoL attributes, and this thus supports the need to include separate $\mathrm{OHQOL}$ assessments for children with $\mathrm{CP}$.

Acknowledgments We would like to express our gratitude to all the staff of all the preschools and special child care centers visited, the parents, and children who participated in the study, and technical officers of the Public Health and Health Ageing Research group, Faculty of Dentistry, HKU.

Open Access This article is distributed under the terms of the Creative Commons Attribution Noncommercial License which permits any noncommercial use, distribution, and reproduction in any medium, provided the original author(s) and source are credited.

\section{References}

1. Rosenbaum, P., Paneth, N., Leviton, A., et al. (2007). A report: the definition and classification of cerebral palsy April 2006. Developmental Medicine and Child Neurology. Supplement, 109, 8-14.

2. Cans, C., \& Guillem, P. (2002). Prevalence and characteristics of children with cerebral palsy in Europe. Developmental Medicine and Child Neurology, 44, 633-640.

3. Yeargin-Allsopp, M., Van Naarden Braun, K., Doernberg, N. S., Benedict, R. E., Kirby, R. S., \& Durkin, M. S. (2008). Prevalence of cerebral palsy in 8-year-old children in three areas of the United States in 2002: A multisite collaboration. Pediatrics, 121, 547-554.
4. Li, S., Lin, Q., \& Liu, J. (2001). Prevalence of childhood cerebral palsy in six provinces in China. Zhonghua Yi Xue Za Zhi., 81, $1220-1223$

5. Jacobsson, B., \& Hagberg, G. (2004). Antenatal risk factors for cerebral palsy. Best Practice \& Research. Clinical Obstetrics \& Gynaecology, 18, 425-436.

6. Rosenbaum, P. (2003). Cerebral palsy: What parents and doctors want to know. BMJ., 326, 970-974.

7. Thorogood, C., Alexander, M. A. (2007). Cerebral palsy. eMedicine: Available at : http://emedicine.medscape.com/article/310740overview, 2007.

8. Reilly, S., Skuse, D., \& Poblete, X. (1996). Prevalence of feeding problems and oral motor dysfunction in children with cerebral palsy: A community survey. Journal of Pediatrics, 129, 877-882.

9. Chong, S. K. (2001). Gastrointestinal problems in the handicapped child. Current Opinion in Pediatrics, 13, 441-446.

10. Dougherty, N. J. (2009). A review of cerebral palsy for the oral health professional. Dental Clinics of North America, 53: 329$338, \mathrm{x}$.

11. Arnaud, C., White-Koning, M., Michelsen, S. I., et al. (2008), Parent-reported quality of life of children with cerebral palsy in Europe. Pediatrics, 121, 54-64.

12. Chan, L. F., Chow, S. M., \& Lo, S. K. (2005). Preliminary validation of the Chinese version of the Pediatric quality of life inventory. International Journal of Rehabilitation Research, 28, 219-227.

13. Lee, G. H., McGrath, C., Yiu, C. K., \& King, N. M. (2009). Translation and validation of a Chinese language version of the Early Childhood Oral Health Impact Scale (ECOHIS). International Journal of Paediatric Dentistry., 19, 399-405.

14. Yuen, K. K. (1974). The two-sample trimmed $t$ for unequal population variances. Biometrika, 61, 165-170.

15. Cohen, J. (1988). Statistical power analysis for the behavioral sciences (2nd ed.). Hillsdale, NJ: Lawrence Earlbaum Associates.

16. Grilli, L., Feldman, D. E., Majnemer, A., Couture, M., Azoulay, L., \& Swaine, B. (2006). Associations between a functional independence measure (WeeFIM) and the pediatric quality of life inventory (PedsQL4.0) in young children with physical disabilities. Quality of Life Research, 15, 1023-1031.

17. Uneri, O. S., Agaoglu, B., Coskun, A., \& Memik, N. C. (2008). Validity and reliability of Pediatric Quality of Life Inventory for 2- to 4-year-old and 5- to 7-year-old Turkish children. Quality of Life Research, 17, 307-315.

18. Li, S., Veronneau, J., \& Allison, P. J. (2008). Validation of a French language version of the Early Childhood Oral Health Impact Scale (ECOHIS). Health and Quality of Life Outcomes, 6,9

19. Pahel, B. T., Rozier, R. G., Slade, G. D. (2007). Parental perceptions of children's oral health: The Early Childhood Oral Health Impact Scale (ECOHIS). Health And Quality Of Life Outcomes, 5, 6.

20. Cochran, W. G. (1977). Sampling techniques (3rd ed.). New York: Wiley.

21. Nuttall, N. M., Steele, J. G., Evans, D., Chadwick, B., Morris, A. J., \& Hill, K. (2006). The reported impact of oral condition on children in the United Kingdom, 2003. British Dental Journal, 200, 551-555.

22. Locker, D. (2007). Disparities in oral health-related quality of life in a population of Canadian children. Community Dentistry and Oral Epidemiology, 35, 348-356.

23. Adamec, C. (1966). The use of Spearman's correlation order coefficient in validation. Ceskoslovenské Zdravotnictví, 14, 100-102.

24. Palisano, R., Rosenbaum, P., Walter, S., Russell, D., Wood, E., \& Galuppi, B. (1997). Development and reliability of a system to classify gross motor function in children with cerebral palsy. Developmental Medicine and Child Neurology, 39, 214-223. 